\title{
THE INFLATIONARY FORCE PRODUCED BY PULMONARY VASCULAR DISTENTION IN EXCISED LUNGS. THE POSSIBLE RELATION OF THIS FORCE TO THAT NEEDED TO INFLATE THE LUNGS AT BIRTH
}

\author{
By MARY ELLEN AVERY,* N. ROBERT FRANK AND IRWIN GRIBETZ † \\ (From the Department of Physiology, Harvard School of Public Health, Department of \\ Pediatrics, Harvard Medical School, and Boston Lying-In Hospital, \\ Boston, Mass.)
}

(Submitted for publication August 18, 1958; accepted October 31. 1958)

Among the forces that may contribute to the first inflation of the lungs after birth, those developed through changes in the pulmonary circulatory system have been assigned primary importance by Jäykkä (1), Bonham Carter (2) and Adams, Karlberg and Lind (3). Possibly the earliest basis for this view was provided during the last century by von Basch (4) who showed in animals and also in experimental models that pulmonary vascular congestion, presumably at the capillary level, tends to increase the volume of gas in the lungs. Recently, it was demonstrated in excised cats' lungs that the expansile force resulting from vascular congestion is greatest when the lungs are collapsed (5). Together, these findings might be taken as evidence underscoring the role of vascular distention in expanding the lungs at birth. Before this view is accepted, however, two facts must be established. One is that the increase in pulmonary blood flow precedes the first breath. This is contrary to the findings of Dawes in fetal lambs that pulmonary blood flow is increased only after inflation has occurred (6). The other is that the force developed through vascular filling or congestion is sufficiently large to cause air to enter the lung. The object of this study was to test this second possibility. Experiments were carried out to compare the distending forces produced by a wide range of pulmonary vascular pressures with the force required to inflate the lungs. Measurements were made on excised lungs of adult cats and dogs that were freed of gas to simulate their condition at birth, and on lungs of puppies and newborn infants that had not breathed.

* This work was supported in part by a Special Traineeship (BT-259) from the National Institute of Neurological Diseases and Blindness, National Institutes of Health.

$\dagger$ Research Fellow, National Foundation for Infantile Paralysis, Inc.
METHODS

Excised lungs from four adult cats, one adult dog, five fetal puppies and two stillborn infants were used. The animal lungs were made gas-free by a modification of the technique of Coryllos and Birnbaum (7). The cats were anesthetized with $30 \mathrm{mg}$. per $\mathrm{Kg}$. of pentobarbital (Nembutal ${ }^{\circledR)} 1$ injected intraperitoneally; the dogs were given the same dose intravenously. Ninety-nine plus per cent of oxygen was used to ventilate the lungs through a tracheal cannula for about 15 minutes, after which the chest was opened and the trachea was occluded to permit absorption of the gas by the pulmonary circulation. Early in the period of gas-freeing $375 \mathrm{mg}$. of mepesulfate $^{2}$ (an anticoagulant), diluted with saline, was injected into the left ventricle. The heart and lungs were excised together. Cannulae were inserted into the pulmonary artery and left atrium; a clamp was put across the myocardium just below the mitral valve in order to close the pulmonary vascular system. Each cannula was connected to a dispensing burette and pressure transducer. To minimize the formation of pulmonary edema, 6 per cent dextran in Ringer's lactate solution was used to fill the blood vessels. Trypan blue was added to the solution to help detect leaks. A tracheal cannula was in-

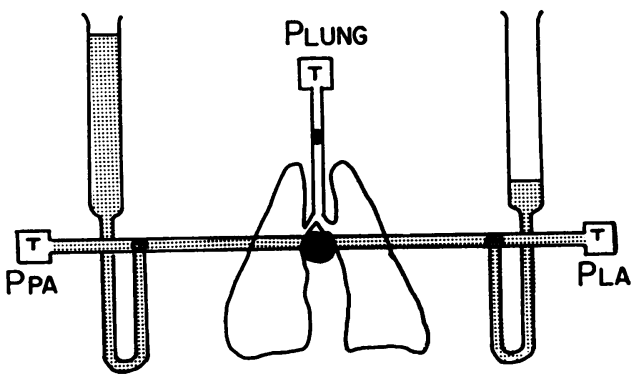

Fig. 1. Schematic Diagram of Burette, Cannulae to Pulmonary Artery and Left Atrium, and IntraTRACHEal Cannula

$\mathrm{T}$ indicates pressure transducer. Cannulae to pulmonary artery and left atrium are represented by black spot between the lungs.

1 Abbott Laboratories.

2 Hoffmann-La Roche, Inc. 


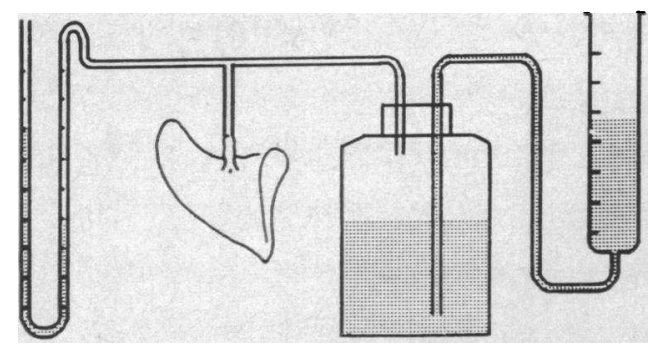

Fig. 2. Diagram of Apparatus for Measuring PresStre-Volume Characteristics of Excised Lobes

A correction for compression of gas within the bottle was made by clamping the trachea, elevating the burette, and subtracting the volume change recorded from the final readings with the lungs in the system.

serted close to the carina and connected to an inductance manometer. The gas volume of the cannula and tubing was kept small, ranging up to approximately $5 \mathrm{ml}$. The apparatus for this part of the experiment is shown schematically in Figure 1.

By varying the height of the dispensing burette leading to the vascular system, pressure could be raised to any level in the pulmonary artery and left atrium. Vascular congestion was maintained approximately 15 seconds,

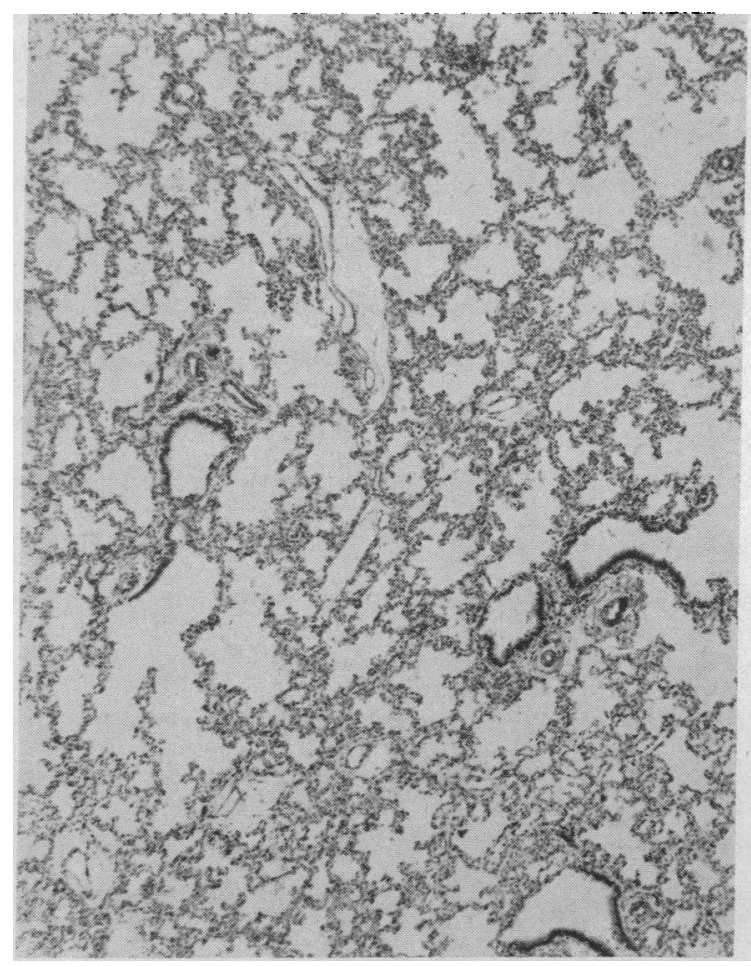

Fig. 3. Section of Right Lung from 1,880 Gm. Stillborn Anencephalic Monster After Vascular Engorgement and Formation of Pulmonary Edema $\times 100$. Hematoxylin and eosin.

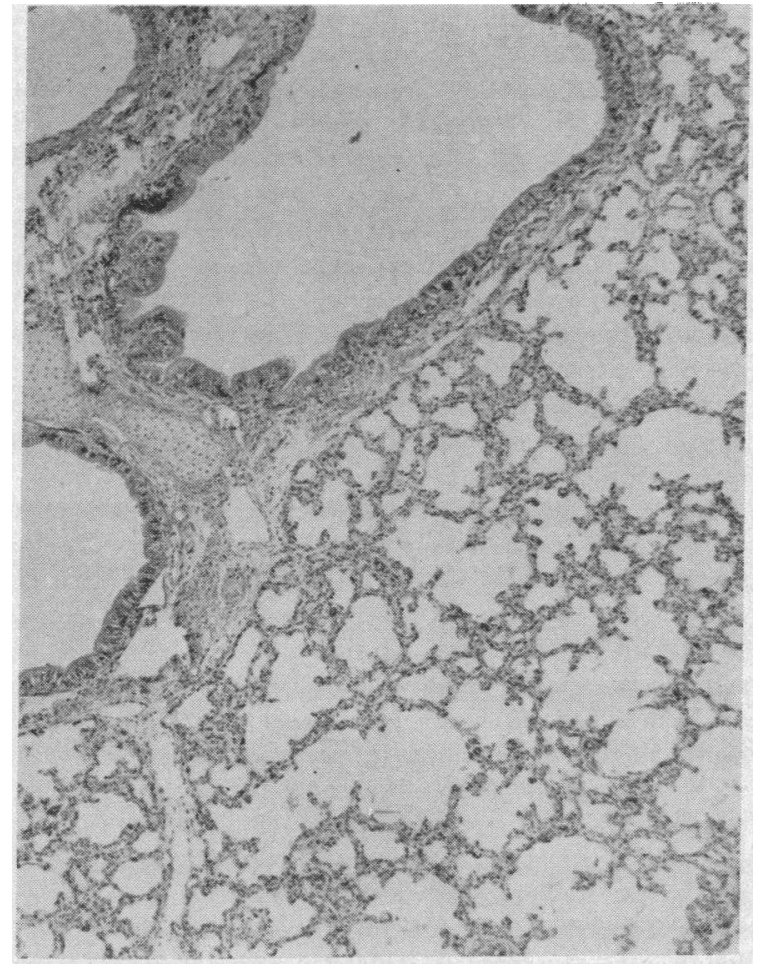

Fig. 4. Section of Left Lung from Same Infant as in Figure 3, After Inflation with Air by Positive Pressure Applied to Trachea

$\times 100$. Hematoxylin and eosin.

unless otherwise stated in the figure legends. Gas was not allowed to enter the lungs during these periods of vascular congestion so that changes only in airway pressure were possible. All pressures were recorded simultaneously on a direct-writing oscillograph.

One human left lung with a weight of $18 \mathrm{Gm}$. was studied four hours after death. It was obtained from a $1,500 \mathrm{Gm}$. anencephalic monster that made no respiratory movements but did have a pulsating heart for 40 minutes after delivery. The other human lung, from an $1,880 \mathrm{Gm}$. anencephalic monster, was studied 7.5 hours after stillbirth. The experimental procedure was the same as that outlined for the animals except that no anticoagulant was used, and the ductus arteriosus was tied off to produce a closed pulmonary vascular system. Histologic sections of the lungs from the $1,880 \mathrm{Gm}$. infant are shown in Figures 3 and 4.

The fetal puppies weighed from 140 to $240 \mathrm{Gm}$. and were obtained from two pregnant dogs estimated to be near term. One of the dogs was sacrificed by injecting Nembutal ${ }^{\circledR}$ intravenously, after which eight puppies were delivered as quickly as possible by cesarean section. Mepesulfate was injected into the fetal hearts which were beating at the time of delivery. The puppies did not breathe during the period of direct observation. The other dog was anesthetized with Nembutal ${ }^{\circledR}$ and the 
lungs ventilated with 99 plus per cent oxygen through a tracheal cannula. An attempt was made to prevent intrauterine respiratory movements by injecting intravenously $0.3 \mathrm{Gm}$. morphine sulfate to sacrifice the animal. Before the puppies were removed from the uterus, the fetal tracheae were clamped; after delivery, the heart and lungs were excised and prepared in the manner already described; in addition, care was taken to occlude the foramen ovale with a clamp placed across the left atrium. Because of the extreme fragility of the cardiovascular tissue, leaks caused by damage to the tissue could not be avoided; as a consequence it was not possible to measure vascular volume, although vascular pressure was recorded accurately.

The preparation used to measure pressure-volume characteristics of excised lungs previously made gas-free is shown schematically in Figure 2. The lungs were obtained from five cats, 2 to $3.5 \mathrm{Kg}$. in weight, and five dogs, 14 to $18 \mathrm{Kg}$. in weight. Elevation of the dispensing burette shown on the right forced gas into the lungs. The difference between fluid levels in the burette and bottle represented the distending pressure for the lungs; this pressure was read from a water-filled manometer. Pressure was raised in steps of $2.5 \mathrm{~cm}$. of water until a large portion of the lungs was inflated; thereafter, steps of 5 $\mathrm{cm}$. of water were used until a peak level of $35 \mathrm{~cm}$. of water (occasionally $30 \mathrm{~cm}$. of water) was reached. The lungs were permitted to deflate in steps of $5 \mathrm{~cm}$. of water. Two minutes were allowed for equilibration to occur before changes in volume were measured. Volume was read directly from the burette after correction was made for compression of the gas. Before and after each run, the volume of the lungs was measured by displacement of fluid.

To determine whether the distending pressure at which gas first entered the lungs could be influenced by the configuration of the lungs, these measurements were also made on individual lobes of dogs' lungs that were partially filled with saline. Two methods were used to instill fluid directly through the bronchial tree, and indirectly through the blood vessels by raising vascular pressure to levels at which "edema" fluid entered the air spaces. The amount of fluid added was roughly equal to the estimated func-

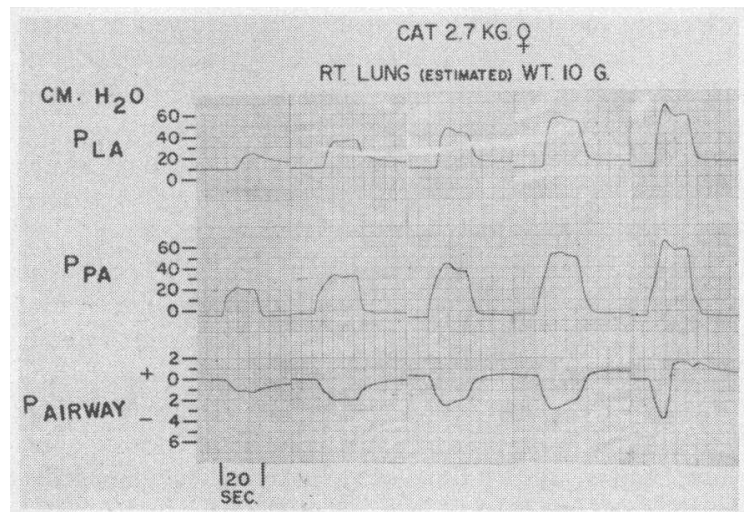

Fig. 5. Pressure Tracings from Gas-Free Cat Lobe

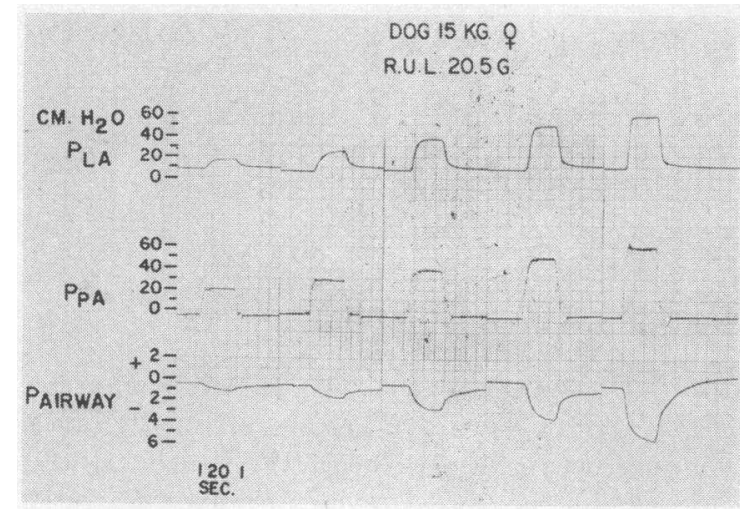

Fig. 6. Pressure Tracings from Gas-Free Dog Lobe

tional residual capacity of the lobe, assuming that the distribution of the functional residual capacity among the lobes is proportional to their weight. Values for the functional residual capacity were based on the data of Mead and Collier (8).

\section{RESULTS}

\section{Influence of acute pulmonary vascular congestion on airway pressure in gas-free excised lungs}

The findings in adult cats' and dogs' lungs were similar. Typical tracings from two experiments are shown in Figures 5 and 6 . The control pulmonary arterial pressure was set at about $-4 \mathrm{~cm}$. of water; in the experiments shown, left atrial pressure during the control period was set at 8 to $10 \mathrm{~cm}$. of water which is within the normal range for the intact animal. In other experiments, control pressure in the left atrium was set at $-4 \mathrm{~cm}$. of water without any apparent difference in results. When arterial pressure was raised acutely to $20 \mathrm{~cm}$. of water or more, pressure in the left atrium rose to nearly the same level within 15 seconds. Filling of the vascular system, judged from the distribution of the blue perfusate, appeared to occur throughout the lungs.

The range of pulmonary vascular pressure was from 20 to $80 \mathrm{~cm}$. of water. Vascular volume and pressure showed a close correlation even though time was not allowed for complete equilibration to occur (Figure 7). At lower vascular pressures, almost all of the fluid was regained upon emptying the system. At vascular pressures of approximately $60 \mathrm{~cm}$. of water or more, the recovery of fluid was incomplete, suggesting that edema or "leakage" had occurred.

In all experiments, the change in airway pres- 


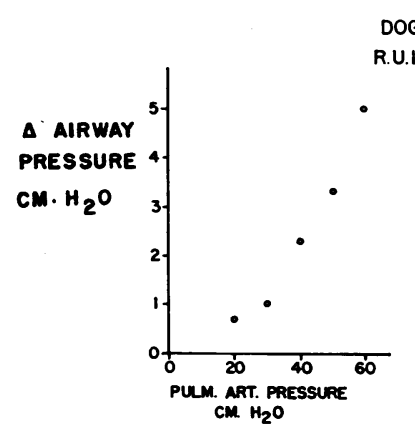

DOG I5 KG. ?

R.U.L. 20.5 G.

Fig. 7. The Relationship Between Pulmonary Vascular Pressure and Volume, and Airway (TransPUlmonary) Pressure

sure followed within a few seconds the onset of congestion. The direction of change was toward subatmospheric; that is, the force which developed acted in the direction of expanding the lungs. (It will be recalled from the description of the preparation that gas was not permitted to enter the lungs.) The change in airway pressure correlated well with the level of vascular pressure, ranging from about $1 \mathrm{~cm}$. of water at a vascular pressure of $20 \mathrm{~cm}$. of water, up to nearly $5 \mathrm{~cm}$. of water at vascular pressures of 50 to $70 \mathrm{~cm}$. of water. The largest distending pressure developed in any lung in this series was $5 \mathrm{~cm}$. of water.

At lower degrees of congestion, airway pressure approached equilibrium asymptotically and returned nearly to control level when congestion was reversed. At the highest vascular pressure, the response was biphasic: Initially, as before, airway pressure became subatmospheric, but it shortly reversed its direction and became positive relative to the atmosphere if the congestion was sustained long enough. This reversal appeared to correspond to formation of increasing amounts of

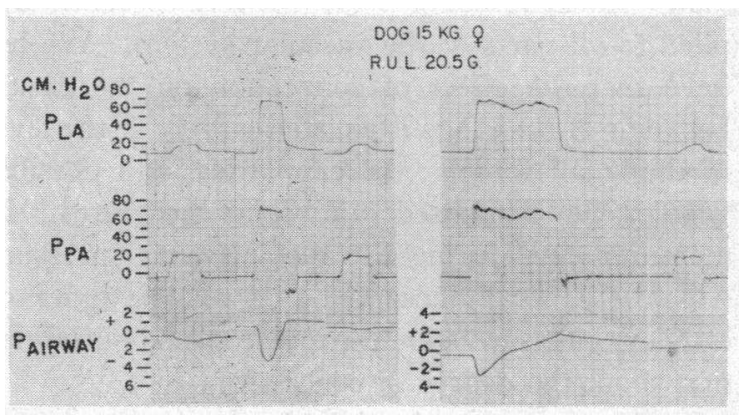

Fig. 8. The Effect of Vascular Congestion on Airway Pressure, Showing the Change in Sign in the Airway During Edema Formation edema. (The lungs were seen to increase significantly in volume.) It is noteworthy that, subsequent to this step, the response of airway pressure to lower levels of vascular pressure was significantly reduced (Figure 8 ).

In the human stillborn lung, pulmonary arterial pressure could not be transmitted to the left atrium. For this reason the procedure was reversed and left atrial pressure was elevated in an attempt to open the vascular system from the other direction. There was no retrograde transmission of pressure either, until atrial pressure reached $80 \mathrm{~cm}$. of water; at this point arterial pressure rose suddenly to about $70 \mathrm{~cm}$. of water. Associated with this extreme elevation of vascular pressure was a slight biphasic change in airway pressure; that is, there was a transient negative phase followed by a positive one (Figure 9).

The results of experiments on fetal puppies were less clear-cut, probably because of leakage out of the vascular system. The largest change induced in airway pressure during filling of the blood vessels was less than $1 \mathrm{~cm}$. of water.

To ensure that pressure changes measured with the gas-filled recording system (tracheal cannula and pressure tubing) were a valid reflection of changes occurring at the alveolar level, two additional procedures were done. One was to place a gas-free cat's lung in an air-tight, stoppered glass jar; the lung was supported by its tracheal cannula leading through the stopper to a transducer; several sizes of cannulae and lengths of tubing

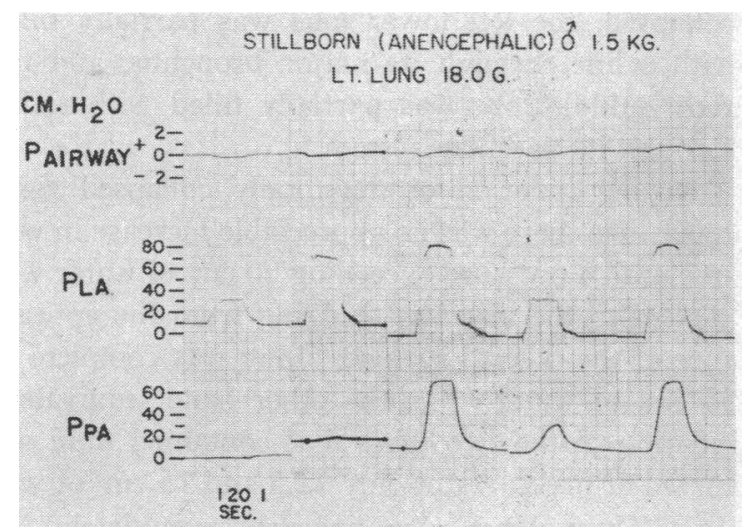

Fig. 9. Pressure Tracings Obtained During Elevation of the Left Atrial Pressure in the Lungs of a Human Stillborn

Note the very minimal changes in airway pressure accompanying vascular distention. 
were used. Suction was then applied around the lungs in steps of $1 \mathrm{~cm}$. of water up to a total of $-6 \mathrm{~cm}$. of water, while the pressure response inside the trachea was recorded. In general, about 80 per cent of the applied negative pressures was transmitted to the manometer; that is, a pressure of $-5 \mathrm{~cm}$. of water around the lungs was read as $-4 \mathrm{~cm}$. of water. The small variations of size of the cannulae and tubing used in the first experiments did not significantly affect this degree of transmission.

The second procedure was to repeat the experiment entirely under fluid (saline). In this system, zero reference pressure for both the lungs and blood vessels was the level of the saline bath. The assumption was made that in the absence of an air-fluid interface the changes in pressure at the alveolar level would be transmitted in total to the manometer. It was found that the magnitude of change in airway pressure induced by graded elevations of vascular pressure were approximately the same as those in the conventional preparation.

\section{Volume-pressure characteristics of the gas-free and partially fuid-filled lungs}

Typical examples of static volume-pressure characteristics of the separate lobes of a dog's lung are shown in Figure 10. To facilitate comparison of the lobes, intrapulmonary volume was expressed in $\mathrm{ml}$. (gas, fluid, or both) per Gm. of tissue. In this preparation the right upper lobe was completely collapsed, the left lower lobe was partially filled with saline through its major bronchus, and the right middle lobe was partially filled with saline through its vascular system.

During inflation of the totally collapsed right upper lobe there was no appreciable increase in volume until a pressure exceeding $20 \mathrm{~cm}$. of water was applied to the airway. Judging from the appearance of the pleural surface, filling was complete at $35 \mathrm{~cm}$. of water. On the other hand, equivalent inflation of the two lobes that contained fluid occurred at pressures of only 12.5 and $15 \mathrm{~cm}$. of water. These lobes also appeared completely inflated (there were no obviously collapsed units on the pleural surface) at a distending pressure of $35 \mathrm{~cm}$. of water. The volume-pressure relationships of these lungs are illustrated in Figure 10.

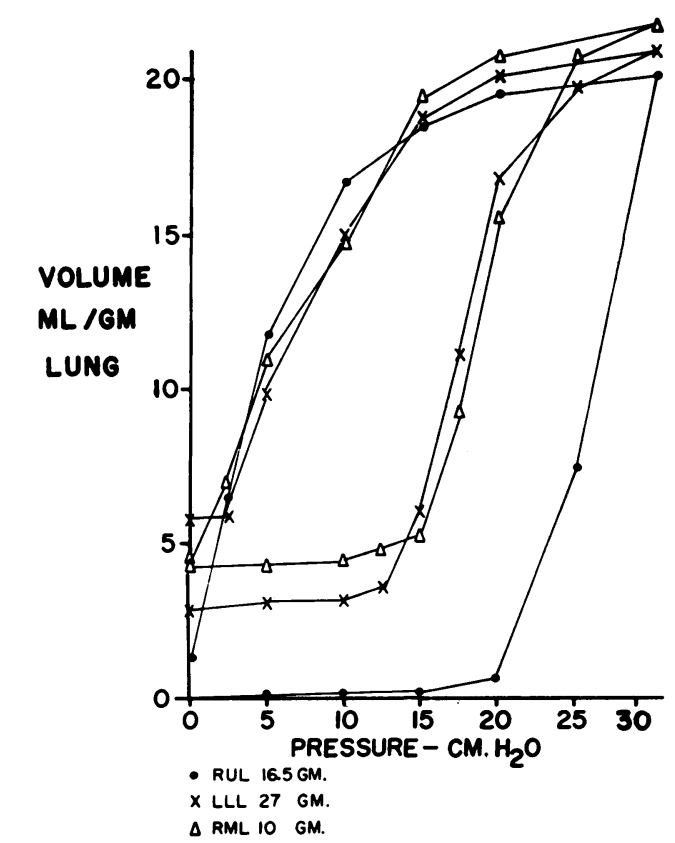

Fig.10. Pressure-Volume Curves of Excised GasFree Dog Lungs

The inflation curves are on the right, deflation on the left. indicates gas- and fluid-free right upper lobe; $\times$, partially filled with saline through bronchus; and $\Delta$, partially filled with saline through the vascular system.

During deflation, the curves for all three lobes were roughly similar except at zero airway pressure at which the volume was greater in the two lobes containing fluid; this occurrence of an increased volume at zero airway pressure in the presence of "edema" is typical for excised lobes (9).

\section{DISCUSSION}

Fluid was allowed to flow into, but not through, the vascular system from either side; approximately equal levels of pressure were therefore applied to all parts of the vascular system. We believe that the effect of congestion on the elastic behavior of the lungs is exerted largely at the level of the small vessels: the capillaries, and possibly venules, lying apposed to alveolar structures. In measurements during life the left atrial pressure which is generally accepted as a reliable index of capillary pressure should provide similar information about the degree of congestion.

In general, the changes produced in airway pressure acting to distend the lungs of the adult dogs and cats were roughly proportional to the 
levels of vascular pressure that were applied. When the vascular pressure was raised to $30 \mathrm{~cm}$. of water, an inflationary force of only 1 to $2 \mathrm{~cm}$. of water was developed; at a vascular pressure of 40 $\mathrm{cm}$. of water it rose to about $2.5 \mathrm{~cm}$. of water; at levels of 60 to $80 \mathrm{~cm}$. of water, the change in airway pressure never exceeded $5 \mathrm{~cm}$. of water. Vascular pressures of 30 to $40 \mathrm{~cm}$. of water have particular relevance, for when these levels are reached in the left atrium of living dogs, pulmonary edema forms (9). The higher vascular pressures in these experiments were induced to test the extreme situation, answering the question of how much effect on airway pressure is possible.

The relative lack of response among the lungs of stillborn infants and fetal dogs may have been due to technical shortcomings : clotted blood which prevented the transmission of pressure throughout the vessels (stillborn infants' lungs) and vascular leaks (fetal dogs' lungs). On the other hand, the presence of amniotic fluid or secretions in the lungs would tend to minimize the expansile effect of vascular congestion. That is, the distending force produced by a given degree of congestion is greatest when the lungs are at minimum volume, and becomes progressively smaller as the lungs expand (5). Evidence for this was found in the experiments in which vascular pressure was maintained at high levels for periods up to several minutes. Airway pressure, which at the outset fell to subatmospheric levels, gradually reversed its direction and finally became positive relative to atmospheric pressure (Figures 5, 6, 8, 9 ). Concurrently, the volume of the lungs, judging from their external appearance, increased significantly even though the trachea was occluded. This suggests that the increasing volume of the lungs did minimize the inflationary effect of vascular distention.

Fluid which may be present in the passages of the lungs prior to initial inflation by gas will have other implications as well. The results of these experiments suggest that if there is fluid equal in amount to half of the estimated functional residual capacity, inflation will proceed at lower distending pressure than if the lungs are totally collapsed (Figure 10). This effect may be due to changes in the configuration of the smaller units of the lung. Fluid, by enlarging the radii of curvature of the alveolar ducts, could facilitate expan- sion in accordance with the LaPlace relationship which states that the pressure in a tube is directly proportional to tension and inversely proportional to the radius of curvature $(P=T / r)$. In the case of air entering a liquid-filled tube, the pressure required would be determined by the surface tension at the liquid-air interface, and the formula would then be $\mathrm{P}=2$ surface tension/radius (10).

The results of these experiments do not support the hypothesis developed by Jäykkä (1) and amplified by Bonham Carter (2) and Adams and co-workers (3), that the force developed by "capillary erection" at birth is a primary factor causing the first inflation of the lungs. Jäykkä's evidence for the hypothesis rested on a series of histological sections from lungs of stillborn infants and animals; vascular congestion had been produced following excision of the lungs. $\mathrm{He}$ found that the lungs were more evenly expanded if macrodex ${ }^{3}$ was first injected through the pulmonary artery than if they were inflated by gas directly through the trachea. The conclusion was drawn that circulatory adjustments at birth are responsible for normal inflation. An alternative explanation for his histological findings is that macrodex which was injected into the pulmonary artery under a pressure of $80 \mathrm{~mm}$. $\mathrm{Hg}$ entered the alveoli as edema fluid, while the particles of India ink used to stain the fluid remained in the capillaries. In the process of fixing the tissue macrodex may have been washed out, giving the illusion of alveoli inflated by gas. Figures 3 and 4 illustrate the difficulty of distinguishing between lungs that are filled with fluid or inflated with gas. Figure 3 shows a section from one lung of an 1,880 $\mathrm{Gm}$. stillborn infant after edema was induced through the vascular system with macrodex stained with trypan blue. The other lung, which was inflated with gas through the trachea, is shown in Figure 4.

\section{SUMMARY}

The role that increased pulmonary blood flow at birth may play in expanding the lungs was studied by measuring the pressures developed in the lungs during acute vascular congestion. Measurements were made in excised lungs of four adult cats, one adult dog, five fetal dogs, and two stillborn infants. When the lungs were at minimum volume,

\footnotetext{
3 Pharmacia Ltd., Sweden.
} 
the effect of vascular distension was in the direction of facilitating expansion but it was not of sufficient magnitude to initiate it. When the lungs were partially distended by fluid, the expansile effect of vascular congestion was negligible.

The presence of a volume of fluid in the lungs, however, while minimizing the effects of vascular congestion, permitted expansion at a lower airway pressure than that required for lungs at minimal volume.

\section{ACKNOWLEDGMENTS}

We are grateful to Dr. James L. Whittenberger and Dr. Clement Smith for their advice and encouragement, and to Dr. Kurt Benirschke and the staff of the Department of Pathology of Boston Lying-In Hospital and Dr. John Craig of the Department of Pathology, Children's Hospital, for permission to study human lungs and for their help with the interpretation of histological sections.

\section{REFERENCES}

1. Jäykkä, S. Capillary erection and lung expansion. Acta paediat. (Uppsala) 1957, 46, Suppl. 112, 9.

2. Bonham Carter, R. E. The architectural function of pulmonary capillaries. Lancet 1957, 1, 1292.
3. Adams, F. H., Karlberg, P., and Lind, J. Possible role of capillary erection as a cause for lung expansion in the newborn infant. Clin. Res. 1958, $6,111$.

4. von Basch, S. S. K. Klinische und Experimentelle Studien, vol. 1. Berlin, August Hirschwald, 1891.

5. Frank, N. R. Effect of acute pulmonary vascular congestion on recoiling force of excised cat lungs. In preparation.

6. Dawes, G. S., Mott, J. C., Widdicombe, J. G., and Wyatt, D. G. Changes in the lungs of the newborn lamb. J. Physiol. 1953, 121, 141.

7. Coryllos, P. N., and Birnbaum, G. L. Studies in pulmonary gas absorption in bronchial obstruction; two new methods for direct and indirect observation. Amer. J. med. Sci. 1932, 183, 317.

8. Mead, J., and Collier, C. Respiratory mechanics in anesthetized dogs. In preparation.

9. Cook, C. D., Mead, J., Schreiner, G. L., Frank, N. R., and Craig, J. M. Pulmonary mechanics during induced pulmonary edema in anesthetized dogs. J. appl. Physiol. In press.

10. Mead, J., Whittenberger, J. L., and Radford, E. P., Jr. Surface tension as a factor in pulmonary volume-pressure hysteresis. J. appl. Physiol. 1957, 10, 191.

\section{ANNOUNCEMENTS OF MEETINGS}

The Fifty-First Annual Meeting of THE AMERICAN SOCIETY FOR CLINICAL INVESTIGATION will be held in Atlantic City, N. J., on Monday, May 4, 1959, at 9:00 A.M. at the Casino Theater on the Steel Pier.

The Sixteenth Annual Meeting of THE AMERICAN FEDERATION FOR CLINICAL RESEARCH will be held in Atlantic City, N. J., at the Casino Theater on the Steel Pier on Sunday, May 3, 1959, at 9:00 A.M.

THE ASSOCIATION OF AMERICAN PHYSICIANS will hold its Seventy-Second Annual Meeting in Altantic City, N. J., at the Casino Theater on the Steel Pier on Tuesday, May 5, 1959, at 9:30 A.M. and in the Vernon Room, Chalfonte-Haddon Hall, on Wednesday, May 6, 1959, at 9:30 A.M. 